\title{
Influence of zonal dosimetry on prostate brachytherapy outcomes
}

\author{
Cheng William Hong, MS!, Chandana A. Reddy, MS², D. Allan Wilkinson, PhD², Eric A. Klein, MD³, Jay P. Ciezki, MD² \\ Lerner College of Medicine, Cleveland Clinic, Cleveland, OH, ${ }^{2}$ Department of Radiation Oncology, Taussig Cancer Institute, Cleveland Clinic, \\ Cleveland, OH, ${ }^{3}$ Department of Urology, Glickman Urological and Kidney Institute, Cleveland Clinic, Cleveland, OH, USA
}

\begin{abstract}
Purpose: To examine the influence of zone-specific dosimetry on outcomes during permanent prostate implantation (PI), where the peripheral zone (PZ) and transitional zone (TZ) may receive varying radiation doses.

Material and methods: Four hundred and sixteen patients treated with I-125 PI (target dose: 144 Gy) between 1996 and 2003 were included in this Institutional Review Board (IRB) approved, retrospective analysis. Whole prostate $(\mathrm{WP}), \mathrm{TZ}$, and PZ were contoured, and zone-specific $\mathrm{D}_{90}$ and $\mathrm{V}_{100}$ were computed. Their influence on biochemical failure (BF) was evaluated using Cox proportional hazards analysis.

Results: The median age and initial prostate-specific antigen (PSA) was 68 years and $6.1 \mathrm{ng} / \mathrm{ml}$, respectively, and the median follow-up time was 8.8 years. There were 329 subjects with Gleason score (GS) 6 disease (79.1\%), and 82 subjects had GS 7 disease (19.7\%). Androgen deprivation therapy (ADT) was used in $20.4 \%$ of patients. Median $\mathrm{D}_{90}$ and $\mathrm{V}_{100 \%}$ in the WP, PZ, and TZ were 141.2 Gy, 156.1 Gy, and 134.5 Gy; and 88.8\%, 93.3\%, and 84.2\%, respectively. Ten-year rates for biochemical recurrence-free survival, distant metastasis-free survival, and prostate cancer-specific mortality were $82.4 \%, 92.4 \%$, and $0.97 \%$ respectively. Only initial PSA, GS7+ disease, ADT, and PSA frequency were significant on multivariate analysis. Ten-year rates of grade 3 or higher GU and GI toxicity was $10.9 \%$ and $1.8 \%$, respectively. $\mathrm{TZ} \mathrm{V}_{200}$ and $\mathrm{TZ} \mathrm{V}_{300}$ were significantly associated with late genitourinary toxicity.

Conclusions: The TZ received significantly lower doses of radiation compared to the PZ. On multivariate analysis, no dosimetric parameter was associated with efficacy. Higher TZ doses may be associated with higher late GU toxicity without improving efficacy.

Key words: prostate cancer, toxicity, zonal dosimetry.

\section{Purpose}

Prostate brachytherapy is commonly used for the definitive treatment of prostate cancer. Brachytherapy using permanent implantation of low-dose-rate (LDR) seeds alone for clinically localized prostate cancer can be achieved in a single outpatient visit. It allows for a higher dose of radiation to be given to the prostate while minimizing radiation exposure to the surrounding normal structures, and has similar efficacy to radical prostatectomy or external beam radiation therapy [1-3]. However, brachytherapy requires accurate placement of radioactive seeds and is more operator-dependent than external beam radiation therapy (EBRT), and implant quality can impact long-term outcome $[4,5]$.

Quality assurance mandates a post-implant computed tomography (CT) scan to ensure proper implant positioning, and dosimetric parameters such as the $\mathrm{D}_{90}$ and $\mathrm{V}_{100}$ of the whole prostate (WP) are used to assess treatment adequacy [6]. The majority of prostate cancers, however, occur in the peripheral zone, and the WP dosimetric parameters do not account for the zonal anatomy of the prostate nor capture the heterogeneity in dose distribution within the prostate $[7,8]$. Herein, the influence of zone-specific dosimetry on rates of biochemical failure and toxicity is described.

\section{Material and methods \\ Study design}

This was an Institutional Review Board (IRB) approved retrospective review of 416 patients treated between 1996 and 2003 at our institution. All patients were treated according to the American Brachytherapy Society (ABS) guidelines for I-125 permanent prostate implantation (PI) (target dose of 144 Gy to the prostate), and no patient was excluded from therapy based on pre-operative urinary function or prostate volume. None of our patients were included in the RTOG 98-05 study. 


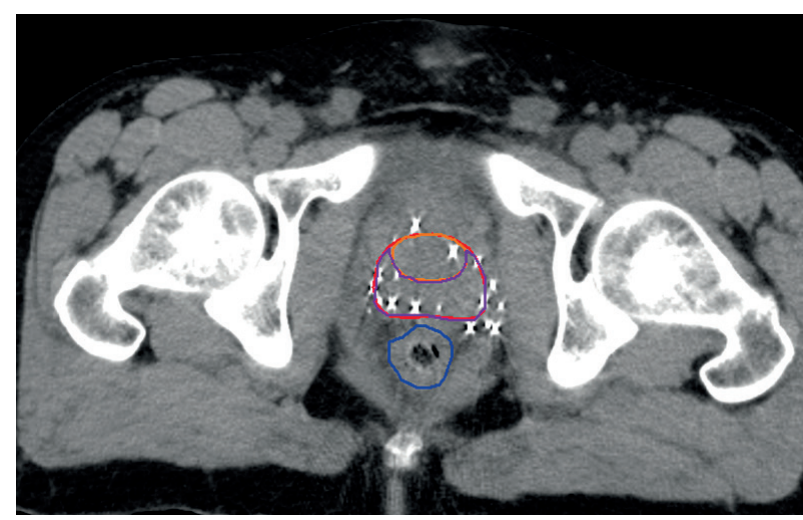

Fig. 1. Transition zone (TZ) (orange) and peripheral zone (PZ) (purple) are contoured on axial slices of the post-implant prostate computed tomography. Whole prostate (WP) (red) and rectum (blue) were already contoured as part of the standard QA process

\section{Brachytherapy technique}

Transrectal ultrasound (TRUS) images of the prostate were obtained at $0.5 \mathrm{~cm}$ intervals using the brachytherapy stepper (Amertek Medical Inc, Singer Island, FL, USA). Intra-operative physics planning was done with a $0.5 \mathrm{~cm}$ radial margin at the apex and base, ensuring that the urethra did not overlap with the $150 \%$ isodose line, and $V_{100 \%}$ of the rectum was less than $1 \mathrm{~cm}^{3}$ (VariSeed 8.0, Varian Medical Systems, Palo Alto, CA) [9]. Rapid strands were placed peripherally and loose seeds were placed centrally; needles were placed beginning with the position furthest from the ultrasound probe to minimize image distortion.

\section{Evaluation of dosimetric quantifiers and clinical variables}

The volumes of the whole prostate were already contoured on post-implant CT scans as part of the standard quality assurance process and calculation of $D_{90}$ and $V_{100}$ for clinical purposes. As the contours by treating physicians were used as a reference for contouring the transitional zone (TZ) and peripheral zone (PZ), the WP was not re-contoured for this study. The TZ was contoured as an area of similar shape to the WP but extending to approximately half of the anterio-posterior diameter of the prostate on axial CT slices (Fig. 1). The PZ was defined to be the remainder of the previously contoured prostate that was not included in the TZ. This method was chosen in order to yield zonal volumes that are consistent with known relative sizes of each zone of the prostate $[10,11]$. Urethral dose was not quantified as imaging was performed without catheter placement. Post-implant dosimetric analysis was performed according to ABS guidelines, and $\mathrm{D}_{90}, \mathrm{D}_{100}, \mathrm{~V}_{100}, \mathrm{~V}_{150}, \mathrm{~V}_{200}, \mathrm{~V}_{300}$, and $\mathrm{V}_{400}$ were calculated for the WP, TZ, and PZ. Pairwise $t$-tests comparing $\mathrm{V}_{100}$ (as a percentage of the zone volume) and $\mathrm{D}_{90}$ (in Gy) between zones of the prostate were done.

Clinical and treatment characteristics were examined as well, including the duration of androgen deprivation therapy (ADT), race, clinical stage, initial prostate-spe-
Table 1. Characteristics of the study population

\begin{tabular}{lcc} 
Characteristic & $\begin{array}{c}\text { Median } \\
\text { or } n\end{array}$ & $\begin{array}{c}\text { Range } \\
\text { or } \%\end{array}$ \\
\hline Age (years) & 68 & $45-87$ \\
\hline Initial PSA & 6.1 & $0.4-33.9$ \\
\hline Race & 366 & 88.0 \\
\hline $\begin{array}{l}\text { Non-African American } \\
\text { African American }\end{array}$ & 50 & 12.0 \\
\hline Clinical T stage & & \\
\hline T1-T2a & 406 & 97.6 \\
\hline T2b or T2c & 10 & 2.4 \\
\hline Initial PSA (ng/ml) & & \\
\hline$<4$ & 41 & 9.9 \\
\hline $4-10$ & 317 & 76.2 \\
\hline $10-20$ & 54 & 13.0 \\
\hline$>20$ & 4 & 1.0 \\
\hline Gleason score & & \\
\hline 6 & 329 & 79.1 \\
\hline 7 & 82 & 19.7 \\
\hline $8-10$ & 5 & 1.2 \\
\hline
\end{tabular}

NCCN risk category

\begin{tabular}{lcc}
\hline Low & 279 & 67.1 \\
\hline Intermediate & 112 & 26.9 \\
\hline High & 25 & 6.0 \\
\hline
\end{tabular}

ADT

\begin{tabular}{lcc}
\hline None & 331 & 79.6 \\
\hline $1-6$ months & 74 & 17.8 \\
\hline$>6$ months & 11 & 2.6
\end{tabular}

Biochemical failure

\begin{tabular}{lcc}
\hline No & 369 & 88.7 \\
\hline Yes & 47 & 11.3
\end{tabular}

Distant metastases

\begin{tabular}{lcc}
\hline No & 398 & 95.7 \\
\hline Yes & 18 & 4.3 \\
\hline Follow-up time (years) & 8.8 & $0.2-15.1$
\end{tabular}

\begin{tabular}{lll}
\hline Follow-up time (years) & 8.8 & $0.2-15.1$ \\
\hline
\end{tabular}

Number of post PI PSA measurements $\quad 9 \quad 0-41$

\begin{tabular}{lll}
\hline PSA frequency (\#PSAs/year) & 1.5 & $0.3-12$
\end{tabular}

Status

\begin{tabular}{lcc}
\hline Alive & 326 & 78.4 \\
\hline Dead, of disease & 5 & 1.2 \\
\hline Dead, other & 85 & 20.4
\end{tabular}

Numbers and percentages are provided for categorical variables; medians and ranges are provided for continuous variables.

$A D T$ - androgen deprivation therapy, PI - prostate implant, NED - no evidence of disease

cific antigen (PSA), Gleason score, National Comprehensive Cancer Network risk stratification, and post PI PSA measurements (Table 1). Biochemical failure was defined using the Phoenix criteria (increase in $2.0 \mathrm{ng} / \mathrm{ml}$ over nadir PSA) [12]. Five-year and 10-year rates for biochemical recurrence-free survival, distant metastasis-free 
survival, and prostate cancer-specific mortality were computed. Only patients with three or more PSA measurements were included in the analysis of biochemical recurrence-free survival, as two PSA measurements are required for the definition of biochemical recurrence, and a third is needed to rule out PSA bounce.

Toxicity data was collected during clinical follow-up visits, and analyzed retrospectively. Toxicity was scored according to Common Terminology Criteria for Adverse Events (CTCAE) version 4.0 criteria, and descriptive statistics for late genitourinary (GU) and gastrointestinal (GI) toxicity was tabulated [13]. Five-year and 10-year rates for grade 3 or higher late GU and GI toxicity were computed using Kaplan-Meier analysis.

\section{Statistical analysis}

Statistical analysis was performed using SAS 9.2 and JMP 9.0 software (SAS Institute, Cary, NC, USA). Cox proportional hazards regression was used to assess clinical and dosimetric parameters as predictors for biochemical failure and late toxicity. Variables found to be significant on univariate analysis and were included in multivariable analysis. All $t$-tests were performed as twotailed analyses, and a significance level of 0.05 was used for all statistical testing.

\section{Results}

\section{Population characteristics}

The median age and initial PSA was 68 years (range: 45-87 years) and $6.1 \mathrm{ng} / \mathrm{ml}$ (range: $0.4-33.9 \mathrm{ng} / \mathrm{ml}$ ), respectively. The median follow-up time for the study population was 8.8 years (range: $0.2-15.1$ years) with a median number of 9 post PI PSA measurements (range: 0-41). The characteristics of the study population are as described in Table 1, and dosimetric measurements and implant characteristics are described in Table 2. Dosimetric parameters are compared between the $\mathrm{WP}, \mathrm{TZ}$, and $\mathrm{PZ}$ (Table 3). As intended by peripheral loading of sources, the TZ received lower doses of radiation than the WP $(p<0.0001)$, which in turn received lower doses than the PZ $(p<0.0001)$.

\section{Biochemical failure}

The 5-year and 10-year rates for biochemical recurrence-free survival were $92.4 \%$ (95\% CI: 89.6-95.3\%) and 82.4\% (95\% CI: 77.2-87.7\%) (Fig. 2). The 5-year and 10-year rates for distant metastasis-free survival were $97.8 \%$ (95\% CI: $96.2-99.4 \%$ ) and $92.4 \%$ (95\% CI: 88.4-96.5\%). The 5-year

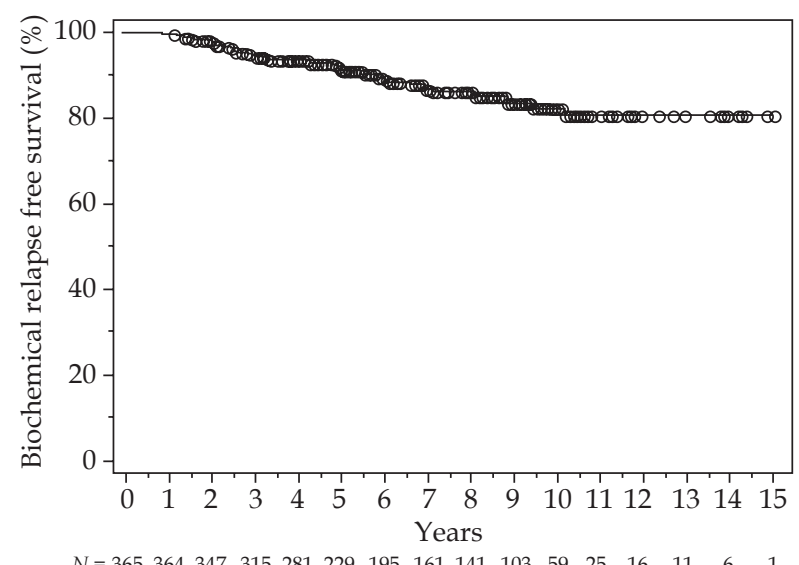

Fig. 2. Kaplan-Meier curve depicting biochemical relapsefree survival. Only patients with three or more PSAs were included for this analysis. $\mathrm{N}$ indicates the number of patients at risk at each time point

Table 2. Intra- and post-implantation variables

\begin{tabular}{lcc} 
Variable & Median & Range \\
\hline Number of sources & 104 & $56-221$ \\
\hline Activity $(\mathrm{U})$ & 0.430 & $0.337-0.546$ \\
\hline Number of needles used & 28 & $16-50$ \\
\hline Pre-PI prostate volume $\left(\mathrm{cm}^{3}\right)$ & 34.5 & $13.7-122.5$ \\
\hline Length $(\mathrm{cm})$ & 4.5 & $2.6-7.0$ \\
\hline Width $(\mathrm{cm})$ & 4.9 & $2.2-7.0$ \\
\hline Height $(\mathrm{cm})$ & 3.1 & $2.0-6.4$ \\
\hline Post-PI prostate volume $\left(\mathrm{cm}^{3}\right)$ & 31.3 & 8.0-115.7
\end{tabular}

$U$-air KERMA units, PI-prostate implant

Table 3. Zone-specific dosimetric parameters assessed on post-implant computed tomography

\begin{tabular}{lcccccc} 
Variable & WP & TZ & PZ & TZ vs. WP & PZ vs. WP & TZ vs. PZ \\
\hline $\mathrm{D}_{90}[$ Gy $($ range $)]$ & $141.2(66.0-222.6)$ & $134.5(55.3-219.5)$ & $156.1(73.4-239.9)$ & $<0.0001$ & $<0.0001$ & $<0.0001$ \\
\hline $\mathrm{D}_{100}[$ Gy $($ range) $]$ & $80.7(32.1-155.2)$ & $91.5(34.5-184.6)$ & $85.5(37.7-155.0)$ & $<0.0001$ & $<0.0001$ & $<0.0001$ \\
\hline Volume $\left[\mathrm{cm}^{3}\right.$ (range) $]$ & $31.3(8.0-115.7)$ & $10.2(1.5-41.8)$ & $20.2(5.9-75.8)$ & - & - & - \\
\hline $\mathrm{V}_{100}[\%$ (range)] & $88.8(39.0-100.0)$ & $84.2(12.6-100.0)$ & $93.3(52.0-100.0)$ & $<0.0001$ & $<0.0001$ & $<0.0001$ \\
\hline $\mathrm{V}_{150}[\%$ (range)] & $52.6(9.7-93.3)$ & $29.0(1.9-94.2)$ & $63.7(11.9-94.4)$ & $<0.0001$ & $<0.0001$ & $<0.0001$ \\
\hline $\mathrm{V}_{200}[\%$ (range)] & $23.6(4.1-64.2)$ & $9.0(0.8-46.5)$ & $31.0(4.5-76.9)$ & $<0.0001$ & $<0.0001$ & $<0.0001$ \\
\hline $\mathrm{V}_{300}[\%$ (range)] & $7.0(2.0-23.9)$ & $3.3(0.0-13.5)$ & $8.5(1.8-32.0)$ & $<0.0001$ & $<0.0001$ & $<0.0001$ \\
\hline $\mathrm{V}_{400}[\%$ (range)] & $3.8(0.6-11.3)$ & $2.0(0.0-6.9)$ & $4.5(1.0-13.9)$ & $<0.0001$ & $<0.0001$ & $<0.0001$
\end{tabular}

Pairwise statistical testing was performed using two-tailed t-tests.

$W P$ - whole prostate, $T Z$ - transition zone, $P Z$ - peripheral zone, $D_{90}$ - minimum dose received by $90 \%$ of the anatomic volume, $D_{100}-$ minimum dose received by $100 \%$ of the anatomic volume, $V_{100}$-volume of the anatomic volume receiving $100 \%$ of the prescribed dose, $V_{150}$-volume of the anatomic volume receiving $150 \%$ of the prescribed dose, $V_{200}$-volume of the anatomic volume receiving $200 \%$ of the prescribed dose, $V_{300}$-volume of the anatomic volume receiving $300 \%$ of the prescribed dose, $V_{400}$ - volume of the anatomic volume receiving $400 \%$ of the prescribed dose 
and 10-year rates for prostate cancer-specific mortality were $0.58 \%$ (95\% CI: 0-1.37\%) and 0.97\% (95\% CI: 0-2.08\%).

On univariate Cox proportional hazards regression analysis, initial PSA, Gleason 7+ disease, duration of ADT, $\mathrm{WP} \mathrm{V}_{100}, \mathrm{TZ} \mathrm{V}_{100}, \mathrm{TZ} \mathrm{D}_{90}, \mathrm{PZ} \mathrm{V_{100 }}$, length and width of the prostate, and PSA frequency were significant predictors for the presence/absence of biochemical failure (Table 4). As PSA frequency is associated with biochemical failure, it was included in the multivariable analysis so that its effect can be adjusted for. On multivariable analysis of these variables, only initial PSA, Gleason 7+ disease, and PSA frequency remained significant (Table 5).

\section{Toxicity}

Thirty-six patients $(8.7 \%)$ developed late grade 3 or higher GU toxicity, whereas 7 patients $(1.7 \%)$ developed late grade 3 or higher GI toxicity (Table 6). The 5-year and 10-year rates of grade 3 or higher GU toxicity was $6.1 \%$ (95\% CI: $3.7-8.6 \%$ ) and $10.9 \%$ (95\% CI: $7.0-14.7 \%$ ). The 5 -year and 10-year rates of grade 3 or higher GI toxicity was $1.8 \%(0.5-3.2 \%)$ and $1.8 \%(0.5-3.2 \%)$. Genitourinary toxicity was classified as obstructive or irritative, and the grade 3 or greater GU toxicity was predominately because of the need to relieve urinary obstruction (94.4\%). On univariate Cox proportional hazards regression, only $\mathrm{V}_{200}$ and $\mathrm{V}_{300}$ in the TZ was significantly associated with grade 3 or higher late GU toxicity (Table 7). Age, race, duration of ADT, activity, prostate volume, length, width, height, TZ $\mathrm{D}_{90}, \mathrm{TZ} \mathrm{V}_{100}, \mathrm{TZ} \mathrm{V}_{150}, \mathrm{TZ} \mathrm{V}_{400}, \mathrm{TZ}_{\text {Volume }}$, BMI, and history

Table 4. Univariate analysis of clinical and dosimetric parameters as predictors for biochemical failure

\begin{tabular}{|c|c|c|}
\hline Variable & Hazard ratio $(95 \% \mathrm{Cl})$ & $p$-value \\
\hline Age & $0.988(0.948-1.031)$ & 0.5815 \\
\hline Race (AA vs. non-AA) & $1.560(0.749-3.250)$ & 0.2348 \\
\hline T2bc vs. T1T2a & $2.618(0.633-10.870)$ & 0.1838 \\
\hline Initial PSA & $1.106(1.045-1.171)$ & 0.0005 \\
\hline Gleason score 7+ & $4.950(2.740-9.009)$ & $<0.0001$ \\
\hline Duration of ADT & $1.129(1.029-1.238)$ & 0.0105 \\
\hline WP $\vee_{100}(\%)$ & $0.973(0.949-0.998)$ & 0.0321 \\
\hline WP D $D_{90}(G y)$ & 0.989 (0.978-1.001) & 0.0746 \\
\hline$T Z \vee_{100}(\%)$ & $0.985(0.969-1.001)$ & 0.0644 \\
\hline TZ D $\mathrm{D}_{90}(\mathrm{~Gy})$ & $0.989(0.978-1.000)$ & 0.0472 \\
\hline$P Z V_{100}(\%)$ & $0.966(0.937-0.995)$ & 0.0238 \\
\hline PZ D $D_{90}$ (Gy) & $0.993(0.983-1.003)$ & 0.1566 \\
\hline Activity (U) & $0.257(0-1276)$ & 0.7542 \\
\hline Length $(\mathrm{cm})$ & $0.559(0.356-0.878)$ & 0.0117 \\
\hline Width $(\mathrm{cm})$ & $0.485(0.328-0.718)$ & 0.0003 \\
\hline Height $(\mathrm{cm})$ & $0.745(0.429-1.291)$ & 0.2938 \\
\hline PSA frequency & $13.766(4.948-38.300)$ & $<0.0001$ \\
\hline $\begin{array}{l}\text { PSA frequency } \\
{ }^{*} \text { BF time }\end{array}$ & $0.986(0.966-1.006)$ & 0.1696 \\
\hline
\end{tabular}

$A A-A f r i c a n$ American, ADT - androgen deprivation therapy, WP - whole prostate, $T Z$ - transition zone, $P Z$ - peripheral zone, $D_{90}$ - minimum dose received by $90 \%$ of the anatomic volume, $V_{100}$ - volume of the anatomic volume receiving $100 \%$ of the prescribed dose, $U$ - air KERMA units, BF-biochemical failure of diabetes were not. Due to the low event rate, Cox proportional hazards regression to identify factors predictive of late grade 3 or higher GI toxicity was not performed.

\section{Discussion}

Although there are established guidelines for PI target dosage, this study demonstrates that radiation dose delivered to the prostate is not uniform. At our institution, the peripheral distribution of sources is intended to reduce radiation dose delivered to the urethra within the constraints of whole prostate dosimetry guidelines.

Based on target dosimetric parameters for the whole prostate, the TZ appears to be underdosed. Yet, on multivariable analysis, neither WP nor zone-specific dosimetry was significantly associated with biochemical failure, suggesting that overall, lower TZ dose is not necessarily associated with worse outcomes. In the absence of significant benign prostate hypertrophy, the PZ constitutes the majority of prostate [14]. The majority of prostate cancers arise from the $\mathrm{PZ}$, which tends to receive a higher treatment dose, using the technique described here, than WP dosimetry would suggest. In this analysis, the 10year rates of late grade 3 or higher GU and GI toxicity was $10.9 \%$ and $1.8 \%$. In addition, the $\mathrm{TZ}$ volume, which receives particularly high doses, as characterized by $V_{200}$ and $V_{300}$, may be associated with increased late GU toxicity, a finding which has been consistently observed in HDR brachytherapy studies having less follow-up than this series [15-17]. This is likely due to islands of high dose that are in close proximity to the urethra. Highdose-rate brachytherapy has the technical advantage of control over post-implant dosimetry, although it is much more invasive than LDR brachytherapy [18]. While there is some evidence to suggest that prostate length is associated with late GU toxicity likely due to greater medial lobe size and correspondingly higher doses to the bladder neck, presumably due to backscatter from the medial

Table 5. Multivariable analysis of clinical and dosimetric parameters, which were significant on univariate analysis as predictors for biochemical failure

\begin{tabular}{lcc} 
Variable & Hazard ratio $(95 \% \mathrm{Cl})$ & $p$-value \\
\hline Initial PSA & $1.123(1.057-1.193)$ & 0.0002 \\
\hline Gleason score 7+ & $4.937(2.507-9.721)$ & $<0.0001$ \\
\hline Duration of ADT & $0.884(0.774-1.010)$ & 0.0696 \\
\hline${\text { WP } V_{100}(\%)}(1.050(0.910-1.210)$ & 0.5045 \\
\hline TZ D $90(\mathrm{~Gy})$ & $0.989(0.963-1.017)$ & 0.4357 \\
\hline PZ $\mathrm{V}_{100}(\%)$ & $0.936(0.835-1.049)$ & 0.2560 \\
\hline Length $(\mathrm{cm})^{\text {Width }(\mathrm{cm})}$ & $0.760(0.447-1.290)$ & 0.3084 \\
\hline PSA frequency & $0.662(0.401-1.090)$ & 0.1052 \\
\hline PSA frequency ${ }^{*} \mathrm{BF}$ & $0.983(0.962-1.004)$ & 0.1113 \\
time & &
\end{tabular}

$A D T$ - androgen deprivation therapy, WP-whole prostate, $T Z$-transition zone, $P Z$ - peripheral zone, $D_{90}$ - minimum dose received by $90 \%$ of the anatomic volume, $V_{100}$-volume of the anatomic volume receiving $100 \%$ of the prescribed dose 
Table 6. Late genitourinary and gastrointestinal toxicity stratified by toxicity grade

\begin{tabular}{lcccc}
$\begin{array}{l}\text { Toxicity } \\
\text { grade }\end{array}$ & $\begin{array}{c}\text { Irritative genitourinary } \\
n(\%)\end{array}$ & $\begin{array}{c}\text { Obstructive genitourinary } \\
n(\%)\end{array}$ & $\begin{array}{c}\text { Total genitourinary } \\
n(\%)\end{array}$ & $\begin{array}{c}\text { Total gastrointestinal } \\
n(\%)\end{array}$ \\
\hline None & $376(90.4 \%)$ & $375(90.1 \%)$ & $335(80.5 \%)$ & $398(95.7 \%)$ \\
\hline Grade 1 & $5(1.2 \%)$ & $0(0 \%)$ & $5(1.2 \%)$ & $3(0.7 \%)$ \\
\hline Grade 2 & $33(7.9 \%)$ & $7(1.7 \%)$ & $40(9.6 \%)$ & $8(1.9 \%)$ \\
\hline Grade 3 & $2(0.5 \%)$ & $33(7.9 \%)$ & $35(8.4 \%)$ & $7(1.7 \%)$ \\
\hline Grade 4 & $0(0 \%)$ & $1(0.2 \%)$ & $1(0.2 \%)$ & $0(0 \%)$ \\
\hline Grade 5 & $0(0 \%)$ & $0(0 \%)$ & $0(0 \%)$ & $0(0 \%)$
\end{tabular}

lobe to the bladder neck, our data did not demonstrate such a relationship [19-21].

The rates of long-term biochemical failure and late toxicities following the use of brachytherapy for prostate cancer with or without EBRT have been investigated in RTOG 00-19 and RTOG 98-05 [22,23]. In RTOG 00-19, which combined brachytherapy with EBRT, there was a $15 \%$ rate of grade 3 or higher GU/GI toxicities after four years, even though the target dose of PI was lowered to 108 Gy to account for the addition of EBRT [22]. In contrast, the rate of late (beyond 9 months) grade 3 toxicities was $3.2 \%$ in RTOG 98-05 using the same protocol management as RTOG 00-19 [23]. The high degree of variation in toxicity may be due to the oversimplification of treating the whole prostate as a single homogenous organ. It is also possible that the grading of toxicity can be highly subjective and that patient selection may play a role. In our series, a simple urethral dilation was graded as a grade 3 GU toxicity as was a TURP or similar procedure, in which prostate tissue was removed to relieve obstruction. We also had no pre-treatment selection bias relative to urinary function while RTOG 98-05 required all patients to have an AUA voiding score of $<18$. Even if $\mathrm{V}_{100}$ and $\mathrm{D}_{90}$ are similar for two patients, there can be substantial differences in dose distributions, suggesting that standard dosimetric parameters may not be fully representative of the implant quality and dose distribution [24]. It is interesting to note that shorter width and length were significant predictors of biochemical failure on univariate analysis, as the $\mathrm{TZ}$ is closer to the $\mathrm{PZ}$, and these glands would be more difficult to implant.

Given the learning curve of prostate brachytherapy, in RTOG 00-19 it would not be unusual that centers with less accrual would deliver higher treatment doses based on dosimetric quantifiers than centers with more experience, as a higher treatment dose is not necessarily a superior treatment $[25,26]$. An even distribution of seeds results in uneven dose distributions, with the central region receiving a higher dose, and an overtreatment of the urethra, as well as surrounding organs may also contribute to higher than expected genitourinary toxicity [27]. In contrast to EBRT, which delivers a relatively homogenous treatment dose to the tissues within the beam, the advantage of brachytherapy is the ability to deliver a higher dose to the prostate as a whole, while being able to manipulate the dose distribution within the prostate to account for zonal anatomy by judicious placement of sources. As such, attention to dose painting is critical for
Table 7. Univariate analysis of clinical and dosimetric parameters as predictors for late grade 3 or higher genitourinary toxicity

\begin{tabular}{|c|c|c|}
\hline Variable & Hazard ratio $(95 \% \mathrm{Cl})$ & $p$-value \\
\hline Age & $1.048(0.997-1.101)$ & 0.0635 \\
\hline Race (AA vs. non-AA) & $0.981(0.381-2.527)$ & 0.9684 \\
\hline Duration of ADT & $0.990(0.870-1.125)$ & 0.8735 \\
\hline Activity (U) & $\begin{array}{c}672.220 \\
(0.048-9.361 E+06) \\
\end{array}$ & 0.1811 \\
\hline Prostate volume & 0.991 (0.969-1.015) & 0.4702 \\
\hline Length $(\mathrm{cm})$ & $0.973(0.615-1.539)$ & 0.9062 \\
\hline Width (cm) & $0.937(0.600-1.461)$ & 0.7727 \\
\hline Height $(\mathrm{cm})$ & $0.599(0.315-1.140)$ & 0.1182 \\
\hline TZ D 90 (Gy) & 0.999 (0.988-1.011) & 0.9131 \\
\hline$T Z \vee_{100}(\%)$ & $1.001(0.981-1.021)$ & 0.9286 \\
\hline$T Z \vee_{150}(\%)$ & $1.008(0.992-1.025)$ & 0.3260 \\
\hline$T Z V_{200}(\%)$ & $1.043(1.004-1.082)$ & $0.0296^{*}$ \\
\hline$T Z V_{300}(\%)$ & $1.163(1.006-1.344)$ & $0.0408^{*}$ \\
\hline$T Z V_{400}(\%)$ & $1.232(0.952-1.595)$ & 0.1132 \\
\hline TZ Volume $\left(\mathrm{cm}^{3}\right)$ & $1.001(0.946-1.059)$ & 0.9762 \\
\hline BMI $\left(\mathrm{kg} / \mathrm{m}^{2}\right)$ & $0.931(0.858-1.012)$ & 0.0920 \\
\hline Diabetes (N vs. Y) & $1.406(0.547-3.623)$ & 0.4786 \\
\hline
\end{tabular}

$A A$ - African American, TZ - transition zone, $B M I$ - body mass index, $D_{90}$ minimum dose received by $90 \%$ of the anatomic volume, $V_{100}$-volume of the anatomic volume receiving $100 \%$ of the prescribed dose, $V_{150}$-volume of the anatomic volume receiving $150 \%$ of the prescribed dose, $V_{200}$-volume of the ana tomic volume receiving $200 \%$ of the prescribed dose, $V_{300}$-volume of the anatomic volume receiving $300 \%$ of the prescribed dose, $V_{400}$-volume of the anatomic volume receiving $400 \%$ of the prescribed dose

tumor control and limiting toxicities. This is especially important for patients at higher risk of significant toxicity, such as those with a history of TURP [28].

Limitations of this study include its retrospective nature, as well as the reflection of outcomes at a single tertiary-care referral center. As prostate zonal anatomy is not clearly visualized on CT, there may be significant variability in contouring, although a standardized method was used in order to minimize this effect [29].

\section{Conclusions}

In conclusion, dose distribution within the prostate can be heterogeneous and standard whole prostate dosimetric parameters based on a prescription dose may not 
be fully representative of implant quality [30]. Acceptable clinical outcomes can be obtained even when the TZ systematically receives a lower radiation dose than the rest of the prostate to spare the urethra. Increased awareness of zonal anatomy of the prostate during treatment planning may reduce late toxicities without sacrificing efficacy.

\section{Acknowledgements}

The work has been presented as a poster at the $56^{\text {th }}$ ASTRO 2014 Annual Meeting.

\section{Disclosure}

Authors report no conflict of interest.

\section{References}

1. Ciezki JP, Klein EA, Angermeier K et al. A retrospective comparison of androgen deprivation (AD) vs. no AD among lowrisk and intermediate-risk prostate cancer patients treated with brachytherapy, external beam radiotherapy, or radical prostatectomy. Int J Radiat Oncol Biol Phys 2004; 60: 1347-1350.

2. Shapiro EY, Rais-Bahrami S, Morgenstern C et al. Long-term outcomes in younger men following permanent prostate brachytherapy. J Urol 2009; 181: 1665-1671; discussion 1671.

3. Vicini FA, Martinez A, Hanks G et al. An interinstitutional and interspecialty comparison of treatment outcome data for patients with prostate carcinoma based on predefined prognostic categories and minimum follow-up. Cancer 2002; 95: 2126-2135.

4. Zelefsky MJ, Kuban DA, Levy LB et al. Multi-institutional analysis of long-term outcome for stages T1-T2 prostate cancer treated with permanent seed implantation. Int J Radiat Oncol Biol Phys 2007; 67: 327-333.

5. Potters L, Morgenstern C, Calugaru E et al. 12-year outcomes following permanent prostate brachytherapy in patients with clinically localized prostate cancer. J Urol 2008; 179: S20-24.

6. Nag S, Beyer D, Friedland J et al. American Brachytherapy Society (ABS) recommendations for transperineal permanent brachytherapy of prostate cancer. Int J Radiat Oncol Biol Phys 1999; 44: 789-799.

7. Nasser NJ, Wang Y, Borg J et al. Sector analysis of dosimetry of prostate cancer patients treated with low-dose-rate brachytherapy. Brachytherapy 2014; 13: 369-374.

8. Spadinger I, Morris WJ, Keyes M et al. Quadrant dosimetry as a predictor of biochemical relapse in 125I prostate brachytherapy. Brachytherapy 2011; 10: 87-97.

9. Wilkinson DA, Lee EJ, Ciezki JP et al. Dosimetric comparison of pre-planned and or-planned prostate seed brachytherapy. Int J Radiat Oncol Biol Phys 2000; 48: 1241-1244.

10. McNeal JE. The zonal anatomy of the prostate. Prostate 1981; 2: 35-49.

11. McLaughlin PW, Troyer S, Berri S et al. Functional anatomy of the prostate: implications for treatment planning. Int J Radiat Oncol Biol Phys 2005; 63: 479-491.

12. Roach M 3rd, Hanks G, Thames H Jr et al. Defining biochemical failure following radiotherapy with or without hormonal therapy in men with clinically localized prostate cancer: recommendations of the RTOG-ASTRO Phoenix Consensus Conference. Int J Radiat Oncol Biol Phys 2006; 65: 965-974.

13. National Institutes of Health, National Cancer Institute. Common Terminology Criteria for Adverse Events (CTCAE) Version 4.0 [Internet], 2010 [cited 2014 May 30]. Available from: http:/ / evs.nci.nih.gov/ftp1/CTCAE/About.html

14. McNeal JE, Redwine EA, Freiha FS et al. Zonal distribution of prostatic adenocarcinoma. Correlation with histologic pattern and direction of spread. Am J Surg Pathol 1988; 12: 897-906.
15. Akimoto T, Katoh H, Noda S et al. Acute genitourinary toxicity after high dose rate (HDR) brachytherapy combined with hypofractionated external-beam radiation therapy for localized prostate cancer: Second analysis to determine the correlation between the urethral dose in HDR brachytherapy and the severity of acute genitourinary toxicity. Int J Radiat Oncol Biol Phys 2005; 63: 472-478.

16. Ghadjar P, Keller T, Rentsch CA et al. Toxicity and early treatment outcomes in low- and intermediate-risk prostate cancer managed by high-dose-rate brachytherapy as a monotherapy. Brachytherapy 2009; 8: 45-51.

17. Ghadjar P, Matzinger O, Isaak B et al. Association of urethral toxicity with dose exposure in combined high-dose-rate brachytherapy and intensity-modulated radiation therapy in intermediate- and high-risk prostate cancer. Radiother Oncol 2009; 91: 237-242.

18. Skowronek J. Low-dose-rate or high-dose-rate brachytherapy in treatment of prostate cancer - between options. J Contemp Brachytherapy 2013; 5: 33-41.

19. Elshaikh MA, Angermeier K, Ulchaker JC et al. Effect of anatomic, procedural, and dosimetric variables on urinary retention after permanent iodine-125 prostate brachytherapy. Urology 2003; 61: 152-155.

20. Pinkawa M, Fischedick K, Treusacher P et al. Dose-volume impact in high-dose-rate Iridium-192 brachytherapy as a boost to external beam radiotherapy for localized prostate cancer - a phase II study. Radiother Oncol 2006; 78: 41-46.

21. Pal RP, Bhatt JR, Khan MA et al. Prostatic length predicts functional outcomes after iodine-125 prostate brachytherapy. Brachytherapy 2011; 10: 107-116.

22. Lee WR, Bae K, Lawton C et al. Late toxicity and biochemical recurrence after external-beam radiotherapy combined with permanent-source prostate brachytherapy: analysis of Radiation Therapy Oncology Group study 0019. Cancer 2007; 109: 1506-1512.

23. Lawton CA, Hunt D, Lee WR et al. Long-term results of a phase II trial of ultrasound-guided radioactive implantation of the prostate for definitive management of localized adenocarcinoma of the prostate (RTOG 98-05). Int J Radiat Oncol Biol Phys 2011; 81: 1-7.

24. D'Souza WD, Thames HD, Kuban DA. Dose-volume conundrum for response of prostate cancer to brachytherapy: summary dosimetric measures and their relationship to tumor control probability. Int J Radiat Oncol Biol Phys 2004; 58 : 1540-1548.

25. Lee WR, deGuzman AF, Bare RL et al. Postimplant analysis of transperineal interstitial permanent prostate brachytherapy: evidence for a learning curve in the first year at a single institution. Int J Radiat Oncol Biol Phys 2000; 46: 83-88.

26. Lee WR, Bae K, Lawton CA et al. A descriptive analysis of postimplant dosimetric parameters from Radiation Therapy Oncology Group P0019. Brachytherapy 2006; 5: 239-243.

27. Wallner K, Roy J, Harrison L. Tumor control and morbidity following transperineal iodine 125 implantation for stage T1/T2 prostatic carcinoma. J Clin Oncol 1996; 14: 449-453.

28. Salembier C, Rijnders A, Henry A et al. Prospective multicenter dosimetry study of low-dose Iodine- 125 prostate brachytherapy performed after transurethral resection. J Contemp Brachytherapy 2013; 5: 63-69.

29. Lee WR, Roach M 3rd, Michalski J et al. Interobserver variability leads to significant differences in quantifiers of prostate implant adequacy. Int J Radiat Oncol Biol Phys 2002; 54: 457-461.

30. Aronowitz JN, Rivard MJ. The phylogeny of permanent prostate brachytherapy. J Contemp Brachytherapy 2013; 5: 89-92. 